\title{
Clinical outcome and virological characteristics of hepatitis B-related acute liver failure in the United States
}

\author{
C.-T. Wai, ${ }^{1}$ R. J. Fontana, ${ }^{1}$ J. Polson, ${ }^{2}$ M. Hussain, ${ }^{1}$ A. O. Shakil, ${ }^{3}$ S.-H. Han, ${ }^{4}$ T. J. Davern, ${ }^{5}$ \\ W. M. Lee, ${ }^{2}$ A. S.-F Lok ${ }^{1}$ and The US Acute Liver Failure Study Group* ${ }^{1}$ Division of Gastroenterology, \\ University of Michigan, Ann Arbor, MI; ${ }^{2}$ Division of Digestive and Liver Diseases, University of Texas Southwestern Medical Center, Dallas, TX; \\ ${ }^{3}$ Division of Gastroenterology, Hepatology and Nutrition, University of Pittsburgh Medical Center, Pittsburgh, PA; ${ }^{4}$ Division of Digestive Diseases, UCLA \\ School of Medicine, Los Angeles, CA; and ${ }^{5}$ Division of Gastroenterology, University of California San Francisco, San Francisco, CA, USA
}

Received March 2004; accepted for publication May 2004

SUMMARY. The role of hepatitis B virus (HBV) genotypes in the outcome of acute HBV infection is unclear. In this study, we aimed to evaluate the clinical and virological features of patients with hepatitis B-related acute liver failure (HBVALF) in the US. Clinical and laboratory features of consecutive patients with HBV-ALF from the US ALF Study Group were analysed. Prevalence of HBV genotypes, precore stop $\left(\mathrm{G}_{1896} \mathrm{~A}\right)$ and core promoter dual $\left(\mathrm{T}_{1762} \mathrm{~A}, \mathrm{~A}_{1764} \mathrm{~T}\right)$ variants among patients with HBV-ALF were compared with a cohort of 530 patients with chronic HBV infection. Thirtyfour HBV-ALF patients were studied: mean age 41 years, $56 \%$ men, 25 had detectable HBV-DNA. HBV genotypes A, $\mathrm{B}, \mathrm{C}$ and $\mathrm{D}$ were found in $36,24,8$ and $32 \%$ patients, respectively. Precore stop and core promoter dual variants were detected in 32 and $44 \%$ of patients, respectively. Twenty-three (68\%) patients survived: 14 after liver trans- plant, nine without transplant. Older age was the only independent factor associated with poor outcome. Compared with patients with chronic HBV infection, patients with ALF were more likely to be non-Asians $(88 \%$ vs $44 \%, P=0.005)$ and to have genotype D (32\% vs $10 \%, P<0.01)$. A higher prevalence of $\mathrm{HBV}$ genotype D persisted even after matching for race and $\mathrm{HBeAg}$ status $(32 \%$ vs $16 \%, P=0.007)$. We concluded that HBV genotype D was more frequently found in patients with HBV-ALF than those with chronic HBV infection in the US. Further studies are needed to determine if $\mathrm{HBV}$ genotypes play a role in the outcome of acute HBV infection.

Keywords: chronic hepatitis B, core promoter variants, HBV genotype, liver transplantation, precore variants.

\section{INTRODUCTION}

Acute liver failure (ALF) is a clinical syndrome characterized by an abrupt onset of jaundice, coagulopathy and encephalopathy in patients without pre-existing liver disease [1]. Approximately $7-19 \%$ of all ALF cases in the UK and the US have been attributed to acute hepatitis B infection [2-4]. Survival in patients with hepatitis B virus-related acute liver failure (HBV-ALF), who do not undergo liver transplant, is

*The US Acute Liver Failure Study Group is given in the Appendix. Abbreviations: AFP, alpha-foetoprotein; ALF, acute liver failure; ALT, alanine aminotransferase; anti-HBc IgM, hepatitis B anti-core IgM antibody; AST, aspartate aminotransferase; $\mathrm{CHB}$, chronic hepatitis B; HBeAg, hepatitis B e antigen; HBsAg, hepatitis B surface antigen; HBV, hepatitis B virus; INR, international normalized ratio; nt, nucleotide; PCR, polymerase chain reaction.

Correspondence: Anna S. F. Lok MD, Division of Gastroenterology, University of Michigan Medical Center, 3912 Taubman Center, Box 0362, Ann Arbor, MI 48109-0362 USA. E-mail: aslok@umich.edu poor, ranging between 19 and 33\% [2-7]. Survival posttransplant is generally $>80 \%[8,9]$, but lifelong immunosuppressive therapy is needed and donor organs may not become available in the short interval from diagnosis to multi-organ failure or cerebral oedema. Therefore, a greater understanding of the clinical outcomes and prognostic indicators of HBV-ALF is important.

Recent studies suggest that HBV genotypes and molecular variants may be important in the outcome of acute and chronic HBV infection [10]. Precore stop codon $\left(\mathrm{G}_{1896} \mathrm{~A}\right)$ and core promoter dual $\left(\mathrm{T}_{1762} \mathrm{~A}, \mathrm{~A}_{1764} \mathrm{~T}\right)$ variants have been found in a higher per cent of patients with HBV-ALF than those with acute self-limiting HBV infection in several studies from Asia [11-13], suggesting that acute infection with these variants might result in a more aggressive course. However, similar studies from the US, France and South Africa failed to confirm the association [14-17]. The reasons for the discrepant results are unclear but may be because of the differences in host factors, hepatitis B e antigen (HBeAg) status at presentation and/or background prevalence of $\mathrm{HBV}$ 
genotypes. Hence, studies that evaluate the role of $\mathrm{HBV}$ variants in HBV-ALF should take into account HBeAg status as well as the prevalence of HBV genotypes and variants among patients with chronic HBV infection in that country.

The aim of this study was to evaluate the clinical features, outcome and prognostic factors in patients with HBV-ALF in the US. We also evaluated the virological characteristics of $\mathrm{HBV}$ in patients with HBV-ALF by comparing the prevalence of $\mathrm{HBV}$ genotypes, precore and core promoter variants between patients with HBV-ALF and those with chronic HBV infection in the US.

\section{PATIENTS AND METHODS}

\section{Patients}

The US Acute Liver Failure Study Group (US ALF) is a consortium of 24 tertiary liver centres interested in determining the aetiology and outcomes of ALF [3]. Consecutive patients from the US ALF Study Group diagnosed as HBV-ALF between January 1998 and July 2002 were included in this study. ALF was defined as the onset of hepatic encephalopathy and coagulopathy within 26 weeks of first symptoms in individuals with no previous liver disease [18]. ALF was attributed to HBV when hepatitis B surface antigen (HBsAg) and/or IgM hepatitis B core antibody (anti-HBc IgM) were present in the serum [19]. Five HBsAg-positive and anti-HBc IgM-negative patients with ALF were excluded: three had documented history of acetaminophen overdose, one was hepatitis $\mathrm{C}$ virus (HCV) antibody, HCV-RNA and hepatitis D virus (HDV) antibody-positive and had ALF probably because of hepatitis $\mathrm{C}$ and/or hepatitis D infection, and the fifth patient had cirrhosis in the explant liver and was considered to have acute exacerbation of chronic hepatitis B rather than acute HBV infection [20]. Another patient who was positive for both anti-HBc IgM and anti-HDV was also excluded as he likely had HBV/HDV co-infection.

Demographics, clinical, laboratory and outcome data, as well as serum samples on all patients with HBV-ALF were retrieved from the coordinating centre at the University of Texas Southwestern Medical Center and sent to Dr Lok's laboratory at the University of Michigan Medical Center for testing and analysis. All clinical data and serum samples were coded to protect the identity of the study subjects. The ALF study protocol specified collection of blood samples for research and was approved by the Institutional Review Board of each of the participating centres. Informed consent was obtained from the next of kin because patients had altered mental status as entry criteria. The protocol of this ancillary study was approved by the Institutional Review Board of the University of Michigan Medical Center.

\section{HBV testing}

Day 1 sera were tested for HBV-DNA by nested polymerase chain reaction (PCR) assays using primers to amplify the HBV surface and precore/core promoter regions, as described previously [19]. For patients in whom day 1 sera were not available, the first available serum samples were analysed. The lower limit of detection of our PCR assay was 250 copies of HBV-DNA per millilitre [19]. Samples with no detectable HBV-DNA were retested using twice as much DNA extract for the first-round PCR and twice the amount of first-round PCR products for the second-round PCR [19]. HBV genotypes, precore stop codon $\left(\mathrm{G}_{1896} \mathrm{~A}\right)$ and core promoter dual variants $\left(\mathrm{A}_{1762} \mathrm{~T}\right.$ and $\left.\mathrm{G}_{1764} \mathrm{~A}\right)$ were determined by line-probe assay (Inno-Lipa; Innogenetics Inc., Ghent, Belgium) as described previously [21]. Samples with indeterminant results in the genotyping assay were analysed (by direct sequencing at the DNA Sequencing Core Facility at the University of Michigan Medical Center), using the standard protocol for the Applied Biosystems DNA sequencer 377 (Perkin Elmer Corp., Foster City, CA, USA) with second-round PCR primers. The precore and core promoter region from nucleotide 1742 to 1933 was sequenced in all samples to detect additional mutations that were not identified by the line-probe assay [19].

\section{Comparison between patients with HBV-ALF and chronic $H B V$ infection}

To determine if specific HBV genotypes and precore/core promoter variants were more prevalent among patients with ALF, virological data from patients in this study, who had detectable HBV-DNA were compared with that obtained in the US HBV Epidemiology Study. The latter study aimed to determine the prevalence of HBV genotype and precore/core promoter variants among patients with chronic HBV infection $(\mathrm{CHB})$ in the US. A total of 694 patients with $\mathrm{CHB}$ from 17 tertiary medical centres distributed across the US were enrolled; eight centres participated in both the US ALF Study and the US HBV Epidemiology Study [6,22]. Of these, 530 had detectable HBV-DNA by PCR and their HBV genotypes and precore/core promoter status were tested by line-probe assays. Comparison of virological results by line-probe assays was initially made between patients with HBV-ALF and all patients in the US HBV Epidemiology Study. Subsequently, a randomly selected cohort of $\mathrm{CHB}$ controls, matched for $\mathrm{HBeAg}$ status and race in a 3:1 ratio, were used as controls. HBeAg status and race were chosen for matching because the prevalence of precore/core promoter variants was related to HBeAg status, while HBV genotype was related to race [6,22].

\section{Statistical analyses}

Data were expressed as mean \pm SEM, unless otherwise stated and were analysed by the SPSS version 10.0 software package (SPSS Inc., Chicago, IL, USA). Spontaneous recovery was defined as survival without liver transplantation. Overall survival was defined as survival with or without transplantation. Poor outcome was defined as having undergone liver transplant or death without liver transplant. 
Categorical variables were compared by chi-square test or Fisher's exact test and continuous variables were compared by the Student's $t$-test, as appropriate. Duration between the onset of symptoms or jaundice and encephalopathy, alanine aminotransferases (ALT) and aspartate aminotransferases (AST) and alpha-fetoprotein (AFP) levels were logarithmically transformed before comparison. Results were considered statistically significant at $P<0.05$. Univariate analysis was performed to identify factors related to spontaneous recovery. The variables analysed include age, gender, race, coma stage, duration between onset of symptoms or jaundice and encephalopathy, bilirubin, ALT and AST level, AST/ ALT ratio, international normalized ratio (INR), AFP, detectable HBV-DNA by PCR, status of HBsAg and HBeAg, HBV genotype, precore stop and core promoter dual mutations. Multivariate analysis was then performed by entering significant factors from univariate analysis with $P<0.05$ into forward logistic regression to identify independent factors associated with spontaneous recovery.

\section{RESULTS}

\section{Characteristics of patients with $H B V-A L F$}

Over the 55-month period, 467 patients were enrolled in the US ALF Study, of whom 34 (7.3\%) were diagnosed as having HBV-ALF. Among the 34 patients with HBV-ALF, 29 (85\%) were HBsAg positive and 27 (79\%) tested anti-HBc IgM positive. The characteristics of the patients at presentation are shown in Table 1. The mean age of the patients was $41 \pm 3$ years, and 19 (56\%) were men; 17 (50\%) were white, 9 (26\%) African-Americans, 4 (12\%) Asians and 4 (12\%) Hispanics.

Twenty-five patients (74\%) had detectable HBV-DNA by PCR. HBV genotype A was the most common (36\%), followed by genotype D (32\%), B (24\%) and C (8\%) (Table 1). Two patients had mixed infection with genotype $\mathrm{B}$ and $\mathrm{C}$ on line-probe assays; line-probe assay as well as direct sequencing revealed that the major genotype was genotype $\mathrm{B}$ in both patients. Eight patients $(32 \%)$ had the precore $\mathrm{G}_{1896} \mathrm{~A}$ mutation. Eleven patients had other precore mutations, the most common being a $\mathrm{G}$ to A change at nucleotide 1899 resulting in glycine to aspartate substitution at codon 29 found in seven patients, five of whom also had the $\mathrm{G}_{1896} \mathrm{~A}$ mutation. Three patients had mutation of the start codon including one who also had the $\mathrm{G}_{1896} \mathrm{~A}$ mutation. Eleven (44\%) patients had the core promoter dual variants and four also had the precore $\mathrm{G}_{1896} \mathrm{~A}$ mutation. Fourteen patients had other core promoter mutations, the most common being $\mathrm{G}_{1757} \mathrm{~A}$ and $\mathrm{C}_{1799} \mathrm{G}$ substitutions.

\section{Outcomes and factors associated with outcomes}

Sixteen patients did not undergo liver transplant: nine had spontaneous recovery and seven died without transplant.
Eighteen patients underwent liver transplantation, 14 were alive at week 3 follow-up visit. Hence, the rates of spontaneous recovery and overall survival were nine of $34(26 \%)$ and 23 of 34 (68\%), respectively.

Comparison of the patients with spontaneous recovery and those with a poor outcome (transplant or death without transplant) showed that patients with spontaneous recovery were significantly younger (mean age $30 \pm 3$ vs $45 \pm 3$ years, $P=0.007$ ) and had a longer interval between onset of symptoms and onset of encephalopathy (mean $16 \pm 3$ vs $11 \pm 3$ days, $P=0.013$ ) than those with a poor outcome (Table 1). Patients with spontaneous recovery also tended to have higher alpha-foetoprotein (AFP) $(305 \pm 188$ vs $38 \pm 21 \mathrm{ng} / \mathrm{mL}, P=0.073)$. None of the virological factors including detectable HBV-DNA by PCR, HBsAg and HBeAg status, HBV genotype or precore/ core promoter variants differed between the two groups. When age and duration between onset of symptoms and onset of encephalopathy were analysed by forward logistic regression, older age was the only independent predictor of poor outcome (OR 1.60, 95\% CI 1.12-2.29, $P=0.011$ ).

Eighteen $(53 \%)$ patients underwent liver transplantation. No difference in demographics or clinical parameters was observed between those who did and did not undergo transplantation. Fourteen of the 18 (78\%) patients who underwent liver transplantation survived. Patients who survived after transplantation were significantly younger $(43 \pm 4$ vs $57 \pm 3$ years, $P=0.025)$ and had higher platelet counts $\left(158 \pm 18 \times 10^{9} / \mathrm{L}\right.$ vs $87 \pm 20 \times 10^{9} / \mathrm{L}$, $P=0.027)$ than those who died post-transplant.

Among the 16 patients who did not undergo liver transplantation, those who had spontaneous recovery had a higher level of AFP (305 \pm 188 vs $1 \pm 0.2 \mathrm{ng} / \mathrm{mL} .2, P=$ $0.007)$ and a lower AST level $(1019 \pm 314$ vs $4687 \pm 1185 \mathrm{IU} / \mathrm{L}, P=0.007)$ than those who died without transplantation.

\section{Comparison of virological factors between patients with $A L F-H B V$ and chronic HBV infection}

To ascertain the role of virological factors in HBV-ALF, results of HBV genotypes, precore/core promoter variants of patients with HBV-ALF and detectable HBV-DNA $(n=25)$ were compared with those with chronic HBV infection from the US HBV Epidemiology Study. Patients with HBV-ALF were less likely to be Asians (12\% vs $56 \%, P=0.001)$ and more likely to be infected with HBV genotype D (32\% vs $10 \%, P<0.01$ ) (Table 2). There was no difference in age, gender or frequency of precore stop or core promoter dual variants between the two groups.

Because the prevalence of HBV genotypes and precore/ core promoter variants are closely related to race and $\mathrm{HBeAg}$ status, we also compared the patients with HBV-ALF with a randomly selected cohort of patients with chronic $\mathrm{HBV}$ infection matched for race and $\mathrm{HBeAg}$ status. Despite 
Table 1 Characteristics of HBV-ALF patients at presentation

\begin{tabular}{|c|c|c|c|c|}
\hline & $\begin{array}{l}\text { All patients } \\
(n=34)\end{array}$ & $\begin{array}{l}\text { Spontaneous } \\
\text { recovery } \\
(n=9)\end{array}$ & $\begin{array}{l}\text { Poor } \\
\text { outcome } \\
(n=25)\end{array}$ & $P$-value \\
\hline Age (years) & $41 \pm 3$ & $30 \pm 3$ & $45 \pm 3$ & 0.007 \\
\hline Male $(\%)$ & $19(56)$ & $7(78)$ & $12(48)$ & 0.24 \\
\hline Race $(\%)$ & & & & 0.53 \\
\hline Whites & $17(50)$ & $6(67)$ & $11(44)$ & \\
\hline African-Americans & $9(26)$ & $2(22)$ & $7(28)$ & \\
\hline Asians & $4(12)$ & 0 & $4(16)$ & \\
\hline Hispanics & $4(12)$ & $1(11)$ & $3(12)$ & \\
\hline Coma stage & $2.8 \pm 0.2$ & $2.3 \pm 0.5$ & $2.9 \pm 0.2$ & 0.27 \\
\hline $\begin{array}{l}\text { Duration between onset } \\
\text { of symptoms and } \\
\text { encephalopathy (days) }\end{array}$ & $13 \pm 2$ & $16 \pm 3$ & $11 \pm 3$ & 0.013 \\
\hline $\begin{array}{l}\text { Duration between onset } \\
\text { of jaundice and } \\
\text { encephalopathy (days) }\end{array}$ & $8 \pm 2$ & $11 \pm 4$ & $7 \pm 3$ & 0.65 \\
\hline $\begin{array}{l}\text { No. of patients with } \\
\text { duration between onset } \\
\text { of jaundice and } \\
\text { encephalopathy } \\
>7 \text { days }(\%)\end{array}$ & $9 / 29(27)$ & $4 / 8(50)$ & $5 / 21(24)$ & 0.21 \\
\hline Creatinine $(\mathrm{mg} / \mathrm{dL})$ & $1.5 \pm 0.2$ & $1.1 \pm 0.2$ & $1.7 \pm 0.3$ & 0.11 \\
\hline Bilirubin (mg/dL) & $16.8 \pm 1.6$ & $17.3 \pm 2.3$ & $16.6 \pm 2.0$ & 0.81 \\
\hline ALT (IU/L) & $3178 \pm 530$ & $1992 \pm 497$ & $3604 \pm 684$ & 0.42 \\
\hline AST (IU/L) & $2391 \pm 414$ & $1019 \pm 314$ & $28905 \pm 613$ & 0.18 \\
\hline ALT/AST ratio & $2.5 \pm 0.4$ & $3.4 \pm 1.2$ & $2.2 \pm 0.4$ & 0.33 \\
\hline INR & $4.9 \pm 0.8$ & $3.3 \pm 0.6$ & $5.5 \pm 1.0$ & 0.21 \\
\hline AFP (ng/L) & $127 \pm 68$ & $305 \pm 188$ & $38 \pm 21$ & 0.073 \\
\hline HBsAg+ $(\%)$ & $29(85)$ & $9(100)$ & $20(80)$ & 0.29 \\
\hline $\mathrm{HBeAg}+(\%)$ & $15 / 31(48)$ & $5 / 9(44)$ & $10 / 22(45)$ & 0.72 \\
\hline Anti-HCV+ $(\%)$ & $1 / 33(3)$ & $1 / 9(9)$ & $0 / 24$ & 0.27 \\
\hline $\begin{array}{l}\text { Serum HBV-DNA+ by } \\
\text { PCR }(\%)\end{array}$ & $25 / 30(83)$ & $7 / 8(88)$ & $18 / 22(82)$ & 1.00 \\
\hline HBV genotype (\%) & & & & 0.68 \\
\hline A & $9(36)$ & $2(29)$ & $7(39)$ & \\
\hline $\mathrm{B}$ & $6(24)$ & $1(14)$ & $5(28)$ & \\
\hline $\mathrm{C}$ & $2(8)$ & $1(14)$ & $1(5)$ & \\
\hline $\mathrm{D}$ & $8(32)$ & $3(43)$ & $5(28)$ & \\
\hline $\begin{array}{l}\text { Precore } \mathrm{G}_{1896} \mathrm{~A} \\
\text { variants }(\%)\end{array}$ & $8 / 25(32)$ & $2 / 7$ (29) & 6/18 (33) & 0.61 \\
\hline $\begin{array}{l}\text { Core promoter TA } \\
\text { variants }(\%)\end{array}$ & $11 / 25(44)$ & $3 / 7(43)$ & $8 / 18(46)$ & 0.65 \\
\hline
\end{tabular}

controlling for race and $\mathrm{HBeAg}$ status, patients with HBVALF were still more likely to be infected with HBV genotype D (32\% vs $16 \%, P=0.007)$.

\section{DISCUSSION}

In this study, the rates of overall survival and spontaneous recovery for patients with HBV-ALF were 67 and 25\% respectively. The spontaneous recovery rate in our patients with HBV-ALF was better than those with Wilson disease $(0 \%)$ but worse than those with acute hepatitis A (65\%)
[3,7]. We found that older age was the only independent factor associated with a poor outcome. Our results were consistent with the King's College criteria and the Clichy criteria, where age was an independent factor associated with mortality, but we were unable to identify any laboratory test that predicted outcome [2,6]. This may be related to the small sample size and differences in host factors. We did not find any relationship between virological factors and overall survival or spontaneous recovery, suggesting that host factors are more important than virological factors in determining outcomes in HBV-ALF. 
Table 2 Comparison between patients with acute liver failure (ALF) and patients with chronic hepatitis B (CHB), who had detectable HBV-DNA

\begin{tabular}{|c|c|c|c|c|c|}
\hline & $\begin{array}{l}\text { ALF } \\
(n=25)\end{array}$ & $\begin{array}{l}\text { All CHB patients } \\
(n=530)\end{array}$ & $P$-value & $\begin{array}{l}\text { Matched CHB } \\
\text { patients }(n=75)\end{array}$ & $P$-value \\
\hline Age (years) & $41 \pm 3$ & $43 \pm 1$ & 0.32 & $46 \pm 2$ & 0.20 \\
\hline Male (\%) & $13(52)$ & $361(68)$ & 0.13 & $53(73)$ & 0.096 \\
\hline Race $(\%)$ & & & 0.005 & & 0.41 \\
\hline Whites & $14(56)$ & $168(31)$ & & $45(60)$ & \\
\hline African-Americans & $6(24)$ & $48(9)$ & & $18(24)$ & \\
\hline Asians & $3(12)$ & $296(56)$ & & $11(15)$ & \\
\hline Hispanics & $2(8)$ & $9(2)$ & & $1(1)$ & \\
\hline Others & 0 & $9(2)$ & & & \\
\hline HBeAg+ (\%) & $14 / 25(56)$ & 196/509 (39) & 0.12 & $40 / 75(53)$ & 1.00 \\
\hline HBV genotype & & & 0.006 & & 0.007 \\
\hline A & $9(36)$ & $184(35)$ & & $54(68)$ & \\
\hline B & $6(24)$ & $117(22)$ & & $4(5)$ & \\
\hline $\mathrm{C}$ & $2(8)$ & $163(31)$ & & $8(11)$ & \\
\hline $\mathrm{D}$ & $8(32)$ & $55(10)$ & & $12(16)$ & \\
\hline Others & 0 & $11(2)$ & & 0 & \\
\hline Precore G1896A variants (\%) & $8(32)$ & $143(27)$ & 0.36 & $12(16)$ & 0.08 \\
\hline Core promoter TA variants (\%) & $11(44)$ & $235(44)$ & 0.57 & $29(39)$ & 0.40 \\
\hline
\end{tabular}

To ascertain the role of virological factors in HBV-ALF, we compared the prevalence of HBV genotypes and precore and core promoter variants between patients with HBV-ALF and patients with chronic HBV infection. A significantly higher percentage of patients with HBV-ALF were infected with $\mathrm{HBV}$ genotype D. In our previous study on US patients with chronic HBV infection, HBV genotype $\mathrm{D}$ was more prevalent among whites and HBeAg-negative patients [23]. In this study, patients with HBV-ALF were significantly less likely to be Asians. This is probably related to the high prevalence of $\mathrm{HBV}$ infection in Asia. Many Asian Americans may have been exposed to HBV at an early age, making them less likely to acquire acute $\mathrm{HBV}$ infection in adult life. After correcting for the potential confounding effects of race and HBeAg status, a significantly higher prevalence of HBV genotype D persisted suggesting that infection with HBV genotype D is more common among patients with HBV-ALF than those with chronic HBV infection in the US. We acknowledge that most if not all patients with ALF likely acquired HBV infection in the US, while $65 \%$ of the patients with CHB were born outside the US and could have acquired HBV infection before moving to the US [23]. Furthermore, 16 of the 24 centres in the US ALF Study Group did not participate in the US HBV Epidemiology Study. Thus, the two groups of patients may have different epidemiological and virological backgrounds.

There have been very few studies comparing the clinical outcome of acute hepatitis B patients infected with different HBV genotypes. A cross-sectional study in Switzerland found that HBV genotype A and D were present in 20 and $80 \%$ of
30 patients with acute hepatitis B and in 89 and $11 \%$ of 35 patients with chronic hepatitis B, respectively [24]. Another study in Japan reported that HBV genotypes A, B and C were found in 10, 39 and $51 \%$, of 61 patients with acute hepatitis B; and in 2, 12 and $86 \%$ of 533 patients with chronic hepatitis B, respectively [25]. The difference in prevalence of HBV genotypes between patients with acute vs chronic HBV infection in the same country suggests that HBV genotypes may play a role in immune response and recovery during acute $\mathrm{HBV}$ infection.

Our study found a higher prevalence of precore stop (32\%) and core promoter dual variants $(44 \%)$ compared with a previous US study $[14,15]$. This may be related to the increased sensitivity of the line-probe assay compared with direct sequencing. It is also possible that there has been a shift in the prevalent HBV genotypes and associated viral variants in the US as a result of changes in immigration patterns.

One major limitation of our study was the small sample size, which may have caused a type II statistical error in determining factors associated with different clinical outcomes. Nevertheless, HBV-ALF is a rare condition and our series is comparable in size to many other studies on this subject and is the largest prospective US study reported to date. Another limitation was the lack of a control group of patients with acute self-limiting HBV infection. Inclusion of such a control group would help determine the role of HBV genotypes in the course of acute HBV infection and the rate of progression to chronic infection. Unfortunately, there is no national database or serum repository for patients with acute self-limiting HBV infection. 
In conclusion, we found that $\mathrm{HBV}$ accounts for $7 \%$ of ALF in the US. Older age was the only predictor of poor outcome. Virological factors including HBV genotypes and precore/core promoter variants did not affect overall survival or the rate of spontaneous recovery among patients with HBV-ALF. However, HBV genotype D was more frequently found in patients with HBV-ALF than those with chronic HBV infection, suggesting that HBV genotype D may be associated with an increased risk of an aggressive course during acute infection and/or a lower risk of progression to chronic infection. Further studies are needed to ascertain the role of $\mathrm{HBV}$ genotypes in the outcome of acute HBV infection.

\section{ACKNOWLEDGEMENTS}

C.T. Wai was supported by the Singapore HMDP Fellowship. The US ALF Study is supported by grant no. R01-DK-58369 (W.M. Lee) from the National Institutes of Health and by the Stephen B. Tips Memorial Fund of the Northwestern Foundation. A.S.F. Lok is supported in part by National Institutes of Health contract N01-DK-9-2323 and grants U01-DK57577, U01-DK-62498 and R43-AI-51919.

\section{REFERENCES}

1 Lee WM. Acute liver failure. N Engl J Med 1993; 329: 1862-1872.

2 O'Grady JG, Alexander GJ, Hayllar KM, Williams R. Early indicators of prognosis in fulminant hepatic failure. Gastroenterology 1989; 97: 439-445.

3 Ostapowicz G, Fontana RJ, Schiodt FV et al. Results of a prospective study of acute liver failure at 17 tertiary care centers in the United States. Ann Intern Med 2002; 137: 947-954.

4 Shakil AO, Kramer D, Mazariegos GV, Fung JJ, Rakela J. Acute liver failure: clinical features, outcome analysis, and applicability of prognostic criteria. Liver Transpl 2000; 6: 163-169.

5 Hou J, Lin Y, Waters J et al. Detection and significance of a G1862T variant of hepatitis B virus in Chinese patients with fulminant hepatitis. J Gen Virol 2002; 83: 2291-2298.

6 Bernuau J, Goudeau A, Poynard T et al. Multivariate analysis of prognostic factors in fulminant hepatitis B. Hepatology 1986; 6: 648-651.

7 Schiodt FV, Davern TJ, Obaid Shakil A, McGuire B, Samuel G, Lee WM. Viral hepatitis-related acute liver failure. Am J Gastroenterol 2003; 98: 448-453.

8 Devarbhavi HC, Cohen AJ, Patel R, Wiesner RH, Dickson RC, Ishitani MB. Preliminary results: outcome of liver transplantation for hepatitis B virus varies by hepatitis B virus genotype. Liver Transpl 2002; 8: 550-555.

9 Steinmuller T, Seehofer D, Rayes N et al. Increasing applicability of liver transplantation for patients with hepatitis B-related liver disease. Hepatology 2002; 35: 1528-1535.

10 Chu CJ, Lok ASF. Clinical significance of hepatitis B virus genotypes. Hepatology 2002; 35: 1274-1276.
11 Omata M, Ehata T, Yokosuka O, Hosoda K, Ohto M. Mutations in the precore region of hepatitis B virus DNA in patients with fulminant and severe hepatitis. $N$ Engl J Med 1991; 324: 1699-1704.

12 Kosaka Y, Takase K, Kojima M et al. Fulminant hepatitis B: induction by hepatitis $\mathrm{B}$ virus mutants defective in the precore region and incapable of encoding e antigen. Gastroenterology 1991; 100: 1087-1094.

13 Sato S, Suzuki K, Akahane Y et al. Hepatitis B virus strains with mutations in the core promoter in patients with fulminant hepatitis. Ann Intern Med 1995; 122: 241-248.

14 Laskus T, Persing DH, Nowicki MJ, Mosley JW, Rakela J. Nucleotide sequence analysis of the precore region in patients with fulminant hepatitis B in the United States. Gastroenterology 1993; 105: 1173-1178.

15 Laskus T, Rakela J, Nowicki MJ, Persing DH. Hepatitis B virus core promoter sequence analysis in fulminant and chronic hepatitis B. Gastroenterology 1995; 109: 1618-1623.

16 Feray C, Gigou M, Samuel D, Bernuau J, Bismuth H, Brechot C. Low prevalence of precore mutations in hepatitis B virus DNA in fulminant hepatitis type B in France. J Hepatol 1993; 18: 119-122.

17 Owiredu WK, Kramvis A, Kew MC. Molecular analysis of hepatitis B virus genomes isolated from Black African patients with fulminant hepatitis B. J Med Virol 2001; 65: 485-492.

18 O'Grady JG, Schalm SW, Williams R. Acute liver failure: redefining the syndromes. Lancet 1993; 342: 273-275.

19 Teo EK, Ostapowicz G, Hussain M et al. Hepatitis B infection in patients with acute liver failure in the United States. Hepatology 2001; 33: 972-976.

20 Perrillo RP. Acute flares in chronic hepatitis B: the natural and unnatural history of an immunologically mediated liver disease. Gastroenterology 2001; 120: 1009-1022.

21 Wai CT, Chu CJ, Hussain M, Lok AS. HBV genotype B is associated with better response to interferon therapy in $\mathrm{HBeAg}(+)$ chronic hepatitis than genotype C. Hepatology 2002; 36: 1425-1430.

22 Chu CJ, Keeffe EB, Han SH et al. Hepatitis B virus genotypes in the United States: results of a nationwide study. Gastroenterology 2003; 125: 444-451.

23 Chu CJ, Keeffe EB, Han SH et al. Prevalence of HBV precore/ core promoter variants in the United States. Hepatology 2003; 38: 619-628.

24 Mayerat C, Mantegani A, Frei C. Does hepatitis B virus (HBV) genotype influence the clinical outcome of $\mathrm{HBV}$ infection? J Viral Hepat 1999; 6: 299-304.

25 Imamura T, Yokosuka O, Tanaka M et al. Distribution of hepatitis B viral genotypes in acute form of liver diseases (abstract). Hepatology 2002; 36: 369A.

\section{APPENDIX}

The US Acute Liver Failure Study Group consists of: William M. Lee (Principal Investigator), University of Texas Southwestern Medical Center, Dallas, Texas; Anne Larson, University of Washington, Seattle, Washington; Jeffery S. Crippin, Washington University, St. Louis, Missouri; 
Timothy J. Davern and Nathan Bass, University of California at San Francisco, San Francisco, California; Michael Schilsky, Mt. Sinai Medical Center, New York, New York; Timothy M. McCashland, University of Nebraska, Omaha, Nebraska; J. Eileen Hay, Mayo Clinic, Rochester, Minnesota Natalie Murray, Baylor University Medical Center, Dallas, Texas; A. Obaid Shakil, University of Pittsburgh, Pittsburgh, Pennsylvania; Andres T. Blei, Northwestern University, Chicago, Illinois; Atif Zaman, Oregon Health Sciences University, Portland, Oregon; Steven H.B. Han, University of California, Los Angeles, Los Angeles, California; Robert J. Fontana, University of Michigan, Ann Arbor, Michigan; Brendan McGuire, University of Alabama at Birmingham, Birmingham, Alabama; Raymond Chung, Massachusetts
General Hospital, Boston, Massachusetts; Steven Lobritto and Robert Brown, Columbia-Presbyterian Medical Center, New York, M. Edwyn Harrison, Mayo Clinic Scottsdale, Phoenix, Arizona; Adrian Reuben, Medical University of South Carolina, Charleston, South Carolina; Santiago Munoz, Albert Einstein Medical center, Philadelphia, Pennsylvania; Thomas Faust, University of Pennsylvania, Philadelphia, Pennsylvania; Todd Stravitz, Virginia Commonwealth University, Richmond, Virgina; Lorenzo Rossaro, University of California, Davis Medical Center, Sacramento, California; Raj Santayanarana, Mayo Clinic, Jacksonville, Florida; Arun Samanta, University of Medicine and Dentistry of New Jersey, Newark, New Jersey. 